\title{
Presentism, persistence and trans-temporal dependence
}

\author{
Jonathan Tallant ${ }^{1}$
}

Published online: 8 August 2017

(C) The Author(s) 2017. This article is an open access publication

\begin{abstract}
My central thesis is that presentism is incompatible with all of the main theories of persistence: endurance, exdurance (stage theory) and perdurance.
\end{abstract}

Keywords Presentism · Persistence $\cdot$ Dependence

\section{Introduction}

Presentism is (typically) defined as the view that: only present objects exist. ${ }^{1}$ This view faces various challenges. ${ }^{2}$ My aim is to introduce a new challenge. My central thesis is that, given various intuitive judgments about dependence, presentism is incompatible with each of the main theories of persistence: endurance, exdurance (or 'stage theory') and perdurance.

In order to develop the argument, I require a brief introduction to each of these theories of persistence, as well as a cursory overview of various claims about dependence. I provide each of these in turn before moving to my arguments purporting to demonstrate the incompatibility of presentism with these dependency claims and theories of persistence. Despite bringing a different argument against

\footnotetext{
${ }^{1}$ There are outliers [see, my, (2014)], but there are a good number of self-identified presentists who assent to this description of their position. E.g. Crisp (2004a, b), Markosian (2004) and Zimmerman (2011).

${ }^{2}$ Not least of which is an objection associated with modern physics. See, e.g., Callender (2008).
}

Thanks to David Ingram for comments on a previous draft.

Jonathan Tallant

jonathan.tallant@nottingham.ac.uk

1 Department of Philosophy, University of Nottingham, Nottingham NG7 2RD, UK 
each theory of persistence, what sits at the core of all of my arguments is that each theory of persistence commits us to trans-temporal dependencies-dependencies that span times. Since the presentist commits themselves to the existence of only present objects, they lack the ontological resources necessary for those dependencies to hold.

\section{Terms and (grounding) conditions}

The accounts of persistence I have in mind can be defined (roughly) as follows.

Perdurance: $\mathrm{x}$ persists from $\mathrm{t}$ to $\mathrm{t} *$ by having a temporal part at each of $\mathrm{t}$ and $\mathrm{t}^{*}$ (and, plausibly, at any time in between). ${ }^{3}$

Endurance: $\mathrm{x}$ persists from $\mathrm{t}$ to $\mathrm{t}^{*}$ by being wholly present at each of $\mathrm{t}$ and $\mathrm{t}^{*}$ (and, plausibly, any time in between). ${ }^{4}$

To illustrate, consider a cat, Tibbles, who persists through time (from to t*). According to perdurance, sometimes called the 'temporal parts' theory of persistence, Tibbles is identified with the whole object that spans $t$ and $t^{*}$ and that has parts at each of those times. ${ }^{5}$ In contrast, according to endurance, Tibbles is wholly present (wholly located) at each of the times through which she persists. She does not have different temporal parts at each of $\mathrm{t}$ and $\mathrm{t}^{*}$.

And so to dependence. There are those who might classify dependence as grounding or at least closely associate the two. Thus, let me get clear on how I am understanding the idea of dependence and how it might connect to grounding. I need to first note three distinct positions: there are those who treat 'grounding' as a primitive term, those who treat the term as standing for a range of different dependence relations, and those who are sceptical about the very notion of grounding. The position that interests me here is the middle one: the view that there are a multiplicity of different kinds of dependence relation (the natures of which I'll spell out shortly) which we can, if we are so minded, describe as a family of 'grounding relations'.

To those who think there is but a single primitive grounding relation [e.g. Schaffer (2009)]: well and good. If you hold that view, then don't think of the relations I describe as 'dependence relations' as being identical to what you call the grounding relation. Rather, think of these relations as a series of modal correlations that seem to hold between physical objects. To those who are sceptical of grounding: again, well and good [e.g. Daly (2012)]. In that case, don't treat the relations I describe as 'grounding' relations. Think of these dependence relations as

\footnotetext{
3 Sider (e.g.) defines the temporal parts as follows: ' $\mathrm{x}$ is an instantaneous temporal part of $\mathrm{y}$ at $\mathrm{t}=(\mathrm{i}) \mathrm{x}$ is a part of $y$ at $t$; (ii) $\mathrm{x}$ exists at, and only at, $\mathrm{t}$; and (iii) $\mathrm{x}$ overlaps at $\mathrm{t}$ everything that is part of $\mathrm{y}$ at t' (Sider 2001: 59). It follows that a persisting object, on this view, is one that is made of more than one such temporal part, for a single part would by itself be instantaneous and so not a persisting entity.

4 See, e.g. Haslanger (1989).

5 Stage theory denies that objects literally persist (Sider 1996: section 6). Since my concern here is with models of persistence, I bracket stage theory from the discussion.
} 
being particular species of modal correlation that seem to hold between physical objects. These caveats noted, let me now turn my attention to the various kinds of dependence relations themselves and the conditions they bring with them.

The specifics of the dependence relations that I wish to discuss here are borrowed from Lowe (2010). First,

Rigid Existential Dependence: $\mathrm{x}$ depends for its existence upon $\mathrm{y}={ }_{\mathrm{df}}$. Necessarily, $x$ exists only if $y$ exists.

According to Lowe (2010: $§ 1)$, this is equivalent to: 'Necessarily, if $x$ exists, then $y$ exists'. The (rigid) 'existential dependence of $\mathrm{x}$ upon $\mathrm{y}$ amounts to the strict implication of y's existence by x's existence'. ${ }^{6}$ Lowe's own example serves to illustrate: necessarily, if Caesar's assassination exists, then Caesar exists. As a consequence, Caesar's assassination rigidly existentially depends upon Caesar's existence. That gives us a flavour of one of Lowe's central notions.

Next, and more important to us, is Lowe's (2010) notion of identity dependence:

Identity Dependence:

$\mathrm{x}$ depends for its identity upon $\mathrm{y}={ }_{\mathrm{df}}$.

There is a function $f$ such that it is part of the essence of $x$ that $x$ is $f(y)$.

Again, borrowing Lowe's example:

'because the identity of a marriage depends on the identities of the two people being married, if $x$ is a marriage and $y$ and $z$ are the two people in question, [Identity Dependence] is satisfied in respect of $x$ and $y$ in virtue of the fact that $x$ is necessarily identical with the marriage of $y$ with $z$ - so that in this case the required function is the marriage with $z$ function from persons to events' (2010: §4).

With these notions in play, let us proceed to the arguments. ${ }^{7}$

\section{Dependence and persistence}

In what follows introduce one argument against each of the potential unions (presentism and perdurance; presentism and endurance), before then introducing one over-arching argument. I argue that various claims about persistence commit us to the truth of certain transtemporal identity dependencies and that presentism lacks the ontological resources for those dependencies to hold. In the section that follows, I consider replies.

\footnotetext{
${ }^{6}$ Lowe also posits generic existential dependence, where the dependence is not on the existence of a specific entity, but on some particular kind of entity (cf. Lowe 2010: §1).

7 Tangentially: each of these kinds of dependence are discussed by Lowe elsewhere (e.g. 1998, 2012) in different contexts and to different ends. I (Tallant 2015) explore the claim that one can recover the kind of grounding relation declared primitive and unanalysable by the likes of Schaffer (2009) via combining these relations. I won't discuss any of these claims here.
} 


\subsection{Presentism and perdurance}

According to the perdurantist (the temporal parts theorist), a persisting object is a mereological sum; it is a collection of temporal parts. What do we know about sums (fusions, wholes, etc.)? We know that sums depend for their identity upon their summands; the identity of a mere heap is fixed by its parts. ${ }^{8} \mathrm{x}$ is the very heap that it is because it has the parts that it does.

So, then: the identity of the persisting (perduring) whole is fixed by the parts. We know that: $\mathrm{x}$ (our persisting whole) depends for its identity upon $\mathrm{y}$ (the parts) $\mathrm{d}_{\mathrm{df}}$. There is a function $\mathrm{f}$ such that it is part of the essence of $\mathrm{x}$ that $\mathrm{x}$ is $\mathrm{f}(\mathrm{y})$. In this case, the obvious candidate for $\mathrm{f}$ is 'having $\mathrm{y}$ as a part', such that it is a part of the essence of this particular (mereological) sum (/heap), $\mathrm{x}$, that it has $\mathrm{y}$ as a part.

The problem? A number of the requisite temporal parts will not be presently existing objects. If they are not present objects, there can be no function from $\mathrm{y}$ to $\mathrm{x}$ of the form 'having $y$ as a part', for not all of the relevant temporal parts exist; not all are present. In that case, the identity of the sum can, at best, be fixed by the function that takes us from a presently existing temporal part, to the sum. In other words, the sum has itself as a part, but not as a proper part. And, since which temporal part exists changes over time, so it turns out that the identity of the sum changes over time (for, as above, a sum's identity is fixed by the identity of its summands). Thus, it turns out that there is no persistence over time, since the identity of the sum changes over time.

An opponent may reply: perhaps it is possible for the temporal parts of $\mathrm{x}$ to not exist, and yet still be a part of $y .{ }^{9}$ This does not help. A non-existing object is not such that the identity of an existing sum can be dependent upon it. For instance, the identity of a heap of stones (e.g.) is fixed by (and only by) those stones that exist and are a part of the heap.

\subsection{Presentism and exdurance (stage theory)}

According to exdurance, an object persists by being counterpart theoretic related to objects at earlier or later times. To borrow an example:

If we accept the stage view, we should analyze a tensed claim such as 'Ted was once a boy' as meaning roughly that there is some past person stage $\mathrm{x}$, such that $\mathrm{x}$ is a boy, and $\mathrm{x}$ bears the I-relation to Ted (Sider 1996: 437) ${ }^{10}$

Similarly, Benovsky (2009: 300):

Consider the claim that Sam is not straight, but he was bent before. The stage view provides a counterpart-theoretic analysis of such a claim: Sam is now straight, but he has a past counterpart that is (was) bent.

\footnotetext{
${ }^{8}$ For argument and discussion, see Lowe (2012: 95).

9 See, e.g., Brogaard (2000). I return to her position in Sect. 4.4.

${ }^{10}$ Sider here is focused on the case of personal identity over time.
} 
Can an exdurantist model be wed to presentism? It cannot. Consider Benovsky's example involving Sam. Qua persisting object, Sam depends for his existence upon the existence of stages that exist at times other than the present. The stages would not be identical to Sam, unless they were counterpart related to Sam. Thus, these other stages depend for their identity on being counterpart theoretic related to Sam. This seems a clear case of identity dependence. But, as in 3.2, we can then raise a concern. The identity of the stages (as stages of Sam) is fixed by their being counterpart theoretic related to Sam. We know that: $x$ (a stage) depends for its identity upon $\mathrm{y}(\mathrm{Sam}) \mathrm{d}_{\mathrm{df}}$. There is a function $\mathrm{f}$ such that it is part of the essence of $\mathrm{x}$ that $\mathrm{x}$ is $\mathrm{f}(\mathrm{y})$. In this case, the obvious candidate for $\mathrm{f}$ is 'being counterpart theoretic related to Sam', such that it is a part of the essence of this particular stage (of Sam) that it is counterpart theoretic related to him. This is clear case of identity dependence. $^{11}$

Of course, stages other than Sam do not exist. Only present objects exist. And, in that case, there are no such past and future stages to be counterpart theoretic related to Sam. It follows from this that Sam doesn't persists, for Sam is not counterpart theoretic related to any earlier or later stage. But of course, Sam was chosen at random. Sam is not special. Exdurance is intended to be a thesis about when persistence occurs under any kind of sortal. As such, it would seem to follow that if exdurance and presentism are true, no objects persist. Of course objects do persist and so presentism faces a problem if wed to exdurance.

\subsection{Presentism and endurance}

Traditional bedfellows they may be, we nonetheless have reason to reject this union. $^{12}$ In order for an object, $\mathrm{O}$, to persist over time, as opposed to simply being an instantaneous object, $\mathrm{O}$ must itself be (wholly) located at more than one time. Thus, the identity of a persisting (enduring) object, as a persisting object, is identity dependent upon its existence at multiple times. There is a function, being an existent at times other than $t$, that $\mathrm{O}$ must saturate in order to be, at $\mathrm{t}$, a persisting object. ${ }^{13}$ Since the existence of $\mathrm{O}$ at $\mathrm{t}$ and at $\mathrm{t}^{*}$ is inconsistent with presentism, so $\mathrm{O}$ does not persist. There are no persisting objects if endurance is true.

\subsection{A general concern}

The final case that I want to bring to the fore is one that threatens the general idea that presentism is compatible with identity over time. I borrow the initial case from Wilson (2017), in a discussion of grounding:

\footnotetext{
11 Benovsky raises a similar concern, though does not focus explicitly on the kind of dependence (identity dependence) relation that is in play. This is a detail. I don't claim that the arguments in this section are clearly original to me.

12 E.g. Hinchliff (1996) and Merricks (1999).

13 Were $\mathrm{O}$ (at $\mathrm{t}$ ) to not exist at times other than $\mathrm{t}$, it would (obviously) still exist. Thus there is no existential dependence in play.
} 
'my being human as opposed to being a swampman may be grounded in my past causal history, and my present ability to refer to Montana may be grounded in my past causal interaction with Montana' (forthcoming: 8)

Focus on the case of the swampman. ${ }^{14}$ The case is familiar, originally described in 'Knowing One's own Mind' (Davidson 1987: 443-4). We are asked to imagine that a lightning strike in a swamp reduces Davidson's body to its basic elements, though simultaneously transforms a nearby tree into a precise replica of Davidson. Call the replica, 'Swampman'. The resulting Swampman is, quite plausibly, not human. In order to be human Swampman would have to be the kind of thing that had a particular past, the right sort of history. Qua human, an entity depends for its identity on having a particular past. In this case, x's history does not exist. If the history does not exist, it cannot be (identity) depended upon. That being so, quite independently of any particular theory of persistence, it turns out that if presentism is true, then no entity is a human being. Since there are humans, so we have a problem for presentism. ${ }^{15}$

\section{Replies}

A number of responses suggest themselves. I consider what I take to be the four most pressing.

\subsection{Truth-maker parallels}

There are a number of similarities between the points that I make and claims that are made by those looking to put a truth-maker objection to presentism (e.g., Sider 2001: 35-42, inter alia). The objection, roughly stated, runs thus:

[1] All truths require truth-makers (i.e. 'ontological grounds').

[2] There are truths about the past.

[3] Truths about the past require existing past objects to ground them.

[4] If presentism is true, there are no existing past objects.

Therefore,

[5] It's not the case that presentism is true.

No presentist will accept the conclusion stated in [5]. Presentists, typically, will deny [3] and augment their ontology, positing presently existing entities to do the truth-making work. Most frequently, presentists will posit Lucretian properties, instantiated by the world (properties of the form, having included $\mathrm{x}$, for whatever $\mathrm{x}$

\footnotetext{
${ }^{14}$ I think the problem of how we ground our present ability to successfully refer is pressing, but would take us away from the problem currently under discussion, a problem that sits at the intersection of time, persistence and dependence.

15 Another interesting case involves the essentiality of origin. If one thinks that $x$ 's current identity is (identity) dependent upon x's origin-i.e., if one holds Kripke's essentiality of origin thesis (cf. Kripke 1980: 111-114) — then presentism faces a problem since, as before, x's past does not exist.
} 
required [e.g., Bigelow 1996)], or abstract times (sets of consistent propositions, ordered by an ersatz B relation, viz. an 'earlier than' or 'later than' relation [e.g., Crisp 2007)]. They will then insist that these presently existing objects are the truthmakers for truths about the past.

This might suggest a parallel strategy: can these presently existing posits not do the ontological work required? If these posits make it true that $O$ was wholly present (e.g.), then, coupled to the present existence of $\mathrm{O}$, that would look to suffice for the truth of $O$ persists.

This general strategy fails for two reasons. First, even were it the case that those presently existing posits made it true that $O$ was wholly present, that's irrelevant to the task in hand. Endurance (e.g.) analyses persistence as a matter of O's being wholly present at a range of times. It does not analyse persistence in terms of it being true that $O$ was wholly present at a range of times. Of course, against an eternalist backdrop, where we assume the existence of objects past, present and future, there is little difference between these two conditions; if it's true that $\mathrm{O}$ is $\mathrm{F}$ at $\mathrm{t}$, then $\mathrm{O}$ exists, at $\mathrm{t}$, and is $\mathrm{F}$. But, on the presentist model, matters are very different. So, to the point of this response: if we analyse the persistence of $\mathrm{O}$ in terms of truths, we aren't adopting either endurance or perdurance; neither view analyses persistence in terms of what is true.

Second, and more tellingly, this seems to give us the wrong kind of putative grounds for trans-temporal identity dependence. To illustrate, consider perdurance. The identity of the perduring sum, I said, depends upon the identity of the summands; it depends upon the identities of the temporal parts. The identity of a sum does not depend upon something that is not a part of that sum (e.g., a presently existing truth-maker). Neither Lucretian properties nor ersatz times are themselves temporal parts of the relevant perduring wholes. Thus, neither are relevant to the identity of the sum; the identity of the sum cannot be said to depend upon them. ${ }^{16}$

\subsection{A 'nefarious' solution}

The range of responses offered by presentists to the truth-maker objection suggests another possible response. Some presentists (including me, see e.g., Tallant \& Ingram 2015) look to deploy 'in virtue of' language, without making any ontological commitments. They deny premise [1]. They tell us that there were dinosaurs is true because there were dinosaurs, where that claim is not one that commits us to the existence of anything in the past or present. More, they say that there were dinosaurs is true in virtue of there having been dinosaurs. Following a position I've argued for with David Ingram (Tallant and Ingram 2015), call this a 'nefarious' response to the truth-maker objection. If that move can be made in response to the truth-maker objection (a significant 'if'), then perhaps something analogous can be done here. Perhaps we can say that, just as true propositions get to be true in virtue of how things were, so (for instance) our perduring whole has its

${ }^{16}$ A structurally similar point can be made about endurance. 
identity in virtue of the way that entities were, without taking that to commit to the further existence of anything over and above what presently exists.

Perhaps, but it's at least a little difficult to see how that story will go. Consider, to illustrate, the case of endurance and presentism. My original argument was that a persisting object, $\mathrm{O}$, is the very kind of thing that it is (i.e. a persisting object), in virtue of $\mathrm{O}$ existing at $\mathrm{t}$ and $\mathrm{O}$ existing at $\mathrm{t}^{*}$ (where $\mathrm{t} \neq \mathrm{t}^{*}$ ). Qua persisting (enduring) object, $\mathrm{O}$ trans-temporally depends for its identity on being located at more than one time. Since the existence of $O$ at $t$ and at $t^{*}$ is inconsistent with presentism (for only present objects exist, and only one of $t$ or $t^{*}$ can be present), so we cannot say that $\mathrm{O}$ is a persisting object.

So, my concern is that there is a trans-temporal identity dependence: a dependence of the present object upon the past. Identity dependence consists in there being a function that takes (at least) one entity as an input and generates an output. Lowe's (2010: §4) example is a useful reminder: the function 'being the marriage of' takes an input from two (existing) people and gives us the identity of the marriage. Simply, then: what kind of function is saturated by a now past, nonexistent entity? ${ }^{17}$ There is no obvious response.

Indeed, it seems to me that the best way to model the problem is not, contra my imagined opponent, the truth-maker objection to presentism. In the truth-making case, that a true proposition is true in virtue of some entity leaves the kind of in virtue of' claim being made somewhat opaque. We are unclear on exactly what is being denoted by this 'in virtue of' claim. That this is the case is precisely what David Ingram and I (and our nefarious kin) look to exploit in response to the truthmaker objection to presentism. But that means this example of a very general 'in virtue of' claim does not obviously give us an example of a trans-temporal identity dependence. It does not give us an obvious parallel. Because of that, the truth-maker literature does not seem the best model to use in trying to capture what the presentist must say in reply to my worries about persistence.

Rather, the best way to model the problem, or so it seems to me, is via the problem of singular propositions that faces presentism (e.g., Markosian 2004: 49-50, inter alia). In brief: supposing that propositions are complex entities, which refer in virtue of being partly constituted by their referent, what entity can constitute a past-tensed singular proposition that refers to a merely past entity? Or, to put the point in the kind of language that I'm using here: referring singular propositions refer, and are the very things that they are, where there is a function 'being a constituent of' that is saturated by the referent of the putative proposition. To give a case, consider: $<$ Caesar crossed the Rubicon $>$. For this proposition to be the very thing that it is, a proposition that directly refers to Julius Caesar, Caesar must exist and constitute the proposition. If Caesar does not exist, then there is no constituent of this putative singular proposition. If there is no constituent, we have no referring

\footnotetext{
17 More: the requirement isn't merely that there not be (e.g.) any such object as Caesar crossing the Rubicon. Rather, the requirement is that the entity's not existing but having existed, which is not itself a category of being, nonetheless serves to saturate the function. There is no obvious way in which to meet that demand.
} 
singular proposition that picks out Caesar; or so goes the standard view [cf. the presentation given in Ingram (2016a, b: 2874-2882)].

Now the answer that most presentists give to this question ("what entity can constitute a past-tensed proposition that refers to a non-existent, merely past entity?') is 'none', or else they try to provide some presently existing surrogate [a point conceded by a good number of presentists—see, e.g. Markosian (2004) and Ingram $(2016 \mathrm{a}, \mathrm{b})]$. The correct lesson to draw from the propositions literature, therefore, seems to be that presentism does not generate trans-temporal identity dependencies. As is clear from the propositions literature, we do not think that a non-existent and now past entity can saturate the function being a constituent of. If that general lesson is correct, then very generally we have no obvious way of saturating a function, $\mathrm{f}$, such that the present identity of some entity identitydepends upon a non-existent, past object. Perhaps a non-obvious solution can be found, but to date there is no such account available.

\subsection{The wrong dependencies}

Much of my argument here has been developed on the assumption that Lowe is correct about the range of dependencies that are in play. If we reject that assumption, then my argument is undermined. So, my opponent says: let us simply deny that those dependencies hold.

Let me raise two concerns with this response. Concern the first: assertion does not make it so. In all of the cases of dependence Lowe describes, reasons are provided for thinking that the dependence holds. So, some unpicking of those arguments and examples, or an independent argument against Lowe, will be required from my opponent.

Concern the second: these dependencies (or something similar to them) really do look to hold in the cases described. For $\mathrm{x}$ to be a perduring object, it must have temporal parts. To be the very object that it is, $\mathrm{x}$ must have exactly the parts that it does (otherwise, it will not be identical to the sum that it is). Thus, $\mathrm{x}$ is transtemporally identity dependent upon its parts. For y to be an enduring object, y must exist at more than one time. Thus, y's being the very kind of thing that it is (a persisting object) trans-temporally identity-depends upon it existing at more than one time. Thus, qua persisting object, $\mathrm{y}$ is identity dependent upon its existence at distinct times. ${ }^{18}$

The overarching point here is that Lowe isn't inventing these dependencies. What Lowe does is draw out the (semi) formal details of a range of different kinds of dependency that are out there in the world. As things turn out, these dependencies are central to the truth of endurance and perdurance. At least so far as I can tell, endurance and perdurance could not be true were these dependencies (or something similar to them) not to hold. Thus, if my opponent is successful in undermining the motivation for thinking that these dependencies hold, then they will be similarly

\footnotetext{
18 Similar remarks go for Al Wilson's case involving my current dependence on my own history in order to be human and not a swampman.
} 
successful in undermining endurance and perdurance. In other words, they will realise my conclusion via another route.

\subsection{Brogaard on temporal parts}

In her Presentist Four-Dimensionalism, Brogaard considers a similar objection to the claim that presentism is compatible with perdurance.

objects are four-dimensional if they have temporal parts, and in order for an object to have temporal parts, these parts must (surely) exist. On the presentist view, only entities that are now wholly present exist. So if Quine is fourdimensional, then it would seem that, on this view, he does not exist. (2000: 346)

However, she also thinks that the presentist has a way around this objection.

This objection too, I shall claim, rests on the idea that objects must have their temporal parts in the same way that they have their spatial parts. That is, temporal parts, like spatial parts, must exist in their entirety. This does indeed hold of those smallest temporal parts which are our successive stages. But it does not hold of temporal parts in general. (2000: 346, my emphasis)

I do not find this argument persuasive. The telling point against the presentist is not, contra Brogaard, that we can draw a distinction between spatial and temporal parts. We can certainly draw such a distinction. What we cannot do, though, on pain of losing any grip on the claim that these are parts of wholes is deny that the relevant dependencies are in play and that the parts of an object must exist in their entirety in order for the whole to do so.

To persuade you that this is the correct approach, I want to take a look at various different kinds of parts-in addition to spatial parts. My general point will be simply that all of these different kinds of wholes require the existence of all of their parts in order to be the very whole that they are. In other words, the existence of the parts determines the identity of the whole and so the identity of the whole is dependent upon the identity of the parts. I will suggest that it is therefore opaque how adding the word 'temporal' in front of the word 'part' serves to generate an important difference. This, I suggest, undermines Brogaard's position.

In addition to the case of spatial parts, already discussed above, I'm going to discuss conceptual parts, (what I will call) spiritual parts and logical parts. Let us start with the case of a conceptual part. Consider the concept 'being a happy person'. I think that it makes sense to suggest that this concept has parts. One part of this concept is the concept 'being happy'. Another part of the concept is 'being a person'. There may be other parts, too, but let's just settle our attention on these two, for now. The concepts 'being happy' and 'being a person' are parts of 'being a happy person'. If either of the concepts 'being happy' or 'being a person' did not exist, then neither would the concept 'being a happy person'. Further, the identity of the concept 'being a happy person' depends upon the concepts 'being happy' and 'being a person'; it is, in a sense, constructed out of them. This is a case where a concept has parts. It can only exist if the parts exist. On the assumption that 
concepts are not (or at least need not be) spatially located, this appears to be another case where a concept can exist and be the very thing that it is if its parts exist.

Let us now consider 'spiritual parts'. Assume, if only for the sake of argument, that God exists, and that the God in question is the God of classical theology. Thus, God exists (in a sense) outside of space and time. God has attributes. One of those attributes is omni-benevolence. Without that attribute-without that part-God would not be identical to the very thing that $\mathrm{He}$ is (a maximally perfect being). Of course, God can only have omni-benevolence as a part if omni-benevolence exists. But God is not located in space and time (at least, so goes the theology). That being so, this is not a spatial part that we are dealing with. We shouldn't worry too much about whether or not God exists. The point is conceptual. The very concept of parthood being invoked in this case is one that requires the existence of the part in order for the whole to be the thing that it is. Moreover, this is not a case where the conceived of whole is spatial and so this is not a case where the parts are spatial parts.

Last, consider logical parts (assuming that these are different from conceptual parts). Consider the logical string: $p \& q \& r$. Call it $L$. $L$ would not be the very logical string that it is, if it had different parts. Thus, $L$ is not identical to the string: $p \& q$. $L$ can only have the parts that it does if those parts exist. The logical string $p \& q \& r$ cannot exist unless each of $p, q$ and $r$ exist. There is no obvious requirement that logical strings are spatially located (it is at least conceivable that scratches on the page that we use to denote logical strings refer to abstract objects). That being so, we would have another case where a whole can exist only where its parts do and where neither the whole nor the parts are obviously spatial.

I cannot see, then, how to make the point more strongly. Where we have an instance of a whole, each of its parts exist, and the identity of the whole depends upon the parts. This is a fact about parts and wholes. It doesn't matter whether the whole (or parts) are spatial. This is just a simple fact about the way that wholes are parts work. The identity of these wholes depends (exclusively) upon the existence of the various parts. It will not do, then, for us to give up on this claim in the temporal case for to do so is in fact to deny that we have a case of parts and wholes. At least, that seems to be the natural conclusion to draw.

\section{Conclusion}

I've argued that presentism is incompatible with each of the main theories of persistence. This puts significant pressure on presentists: they must tell us what persistence is or deny that there are persisting objects. Both options are challenging, but at least one option is a challenge presentists must meet.

Open Access This article is distributed under the terms of the Creative Commons Attribution 4.0 International License (http://creativecommons.org/licenses/by/4.0/), which permits unrestricted use, distribution, and reproduction in any medium, provided you give appropriate credit to the original author(s) and the source, provide a link to the Creative Commons license, and indicate if changes were made. 


\section{References}

Benovsky, J. (2009). Presentism and persistence. Pacific Philosophical Quarterly, 90, 291-309.

Bigelow, J. (1996). Presentism and properties. Philosophical Perspectives, 10, 35-52.

Brogaard, B. (2000). Presentist four-dimensionalism. The Monist, 83, 341-356.

Callender, C. (2008). Finding "real" time in quantum mechanics. In W. L. Craig \& Q. Smith (Eds.), Einstein, relativity and absolute simultaneity (pp. 50-72). London: Routledge.

Crisp, T. (2004a). On presentism and triviality. In D. Zimmerman (Ed.), Oxford studies in metaphysics (1st ed., pp. 15-20). Oxford: OUP.

Crisp, T. (2004b). Reply to Ludlow. In D. Zimmerman (Ed.), Oxford studies in metaphysics (1st ed., pp. 37-46). Oxford: OUP.

Crisp, T. (2007). Presentism and the grounding objection. Nous, 41, 90-109.

Daly, C. (2012). Scepticism about grounding. In F. Correia \& B. Schneider (Eds.), Metaphysical grounding (pp. 81-100). Cambridge: CUP.

Davidson, D. (1987). Knowing one's own mind. Proceedings and Addresses of the American Philosophical Association, 61, 441-458.

Haslanger, S. (1989). Persistence, change and explanation. Philosophical Studies, 56, 1-28.

Hinchliff, M. (1996). The puzzle of change. Philosophical Perspectives, 10, 119-136.

Ingram, D. (2016a). The virtues of thisness presentism. Philosophical Studies, 173, 2867-2888.

Ingram, D. (2016b). Thisnesses, propositions and truth, Pacific Philosophical Quarterly. doi:10.1111/ papq.12181. (forthcoming).

Kripke, S. (1980). Naming and necessity. Oxford: Blackwell.

Lowe, E. J. (1998). The possibility of metaphysics. Oxford: Clarendon.

Lowe, E. J, 2010. Ontological dependence. In E. N. Zalta (Ed.), The Stanford Encyclopedia of Philosophy (Spring 2010 Edition). <http://plato.stanford.edu/archives/spr2010/entries/dependence-ontological/ $>$.

Lowe, E. J. (2012). Against monism. In P. Goff (Ed.), Spinoza on monism (pp. 92-122). London: Palgave Macmillan.

Markosian, N. (2004). A defense of presentism. In D. Zimmerman (Ed.), Oxford studies in metaphysics (1st ed., pp. 47-82). Oxford: OUP.

Merricks, T. (1999). Persistence, parts, and presentism. Nous, 33, 421-438.

Schaffer, J. (2009). On what grounds what. In D. Chalmers, D. Manley, \& R. Wasserman (Eds.), Metametaphysics (pp. 347-383). Oxford: OUP.

Sider, T. (1996). All the world's a stage. Australasian Journal of Philosophy, 74, 433-453.

Sider, T. (2001). Four dimensionalism. Oxford: OUP.

Tallant, J. (2015). Ontological dependence in a spacetime world. Philosophical Studies, 172, 3101-3118.

Tallant, J., \& Ingram, D. (2015). Nefarious presentism. Philosophical Quarterly, 65, 355-371.

Wilson, A. (2017). Metaphysical causation, Noûs. doi:10.1111/nous.12190. (forthcoming).

Zimmerman, D. (2011). Presentism and the space-time manifold. In C. Callender (Ed.), The Oxford handbook of philosophy of time (pp. 163-244). Oxford: OUP. 